\title{
Processing of Hollow Glass Microspheres (HGM) filled Epoxy Syntactic Foam Composites with improved Structural Characteristics
}

https://doi.org/10.1515/secm-2021-0011

Received Aug 10, 2020; accepted Nov 30, 2020

\begin{abstract}
The objective of this work is to improve the structural characteristics of hollow glass microsphere (HGM) filled epoxy syntactic foam composites with little voids content and improved HGM dispersion in the composite.

A modified degassing technique has been introduced during resin casting process of the HGM filled syntactic foam composites. The effect of HGM content volume fractions $(5-25 \%)$ on the degassing techniques was examined. The syntactic foam composites were characterized by analysing structural morphology using Scanning Electron Microscopy (SEM), Transmission Electron Microscopy(TEM), and density measurements (theoretical and experimental).

Less than 5\% void content has been achieved in this study. This resulted in improved tensile and dynamic mechanical properties (DMA).
\end{abstract}

Keywords: Hollow glass microsphere (HGM), syntactic foam, tensile properties, degassing, fracture mechanism

\section{Introduction}

Syntactic foam composites forms cellular structure and are entirely different from the commonly used foams such as polyvinyl chloride (PVC) and poly urethane (PU), geopolymer foam because of their isotropic nature and randomness of their microstructure [1, 2]. Thermoset resins such as epoxy are commonly used as binder or matrix and are widely used in structural applications and in adhesives. Hollow glass microspheres (HGM) are one of the common microballoons used for the development of syntactic foam.

\footnotetext{
${ }^{\star}$ Corresponding Author: T. P Mohan: Composite Research Group (CRG), Department of Mechanical Engineering, Durban University of Technology. Durban, South Africa; Email: mohanp@dut.ac.za Olusegun A. Afolabi, Krishnan Kanny: Composite Research Group (CRG), Department of Mechanical Engineering, Durban University of Technology. Durban, South Africa
}

This HGM is embedded in a polymer material to form syntactic foam composites. The hollow particles may sometimes be in the form of metal, carbon, ceramics, or polymer $[1,3]$. Furthermore, thermoset resins such as epoxy are generally used as a binder for combining of microballoons, which produces composite material with improved properties. Composite material developed from this combination is widely used in structural applications due to its low cost, excellent specific strength, and ease of processing $[4,5]$.

There is a need to produce a lightweight material for the structural application that is economically friendly and fire retardant. Syntactic foams have been studied to fit into this aspect because they are known to be of good advantages for construction purposes due to their reduced weight thus making them applicable as core materials for structural and marine applications [6]. The use of HGM and their synergistic effect as filler in syntactic foam composites gives lightweight, resistances to bending, compressive stress and low thermal conductivity exceeding other foams [5-7].

Syntactic foam is a composite material which exhibits the same density before and after curing. Such low-density syntactic foam is employed in composite tooling for the manufacturing of aerospace structures $[1,5,6]$. Numerous studies have reported significant improvement in the mechanical properties of syntactic foam by changing the amount of filler particles. It was also noted that the properties of the resulting syntactic foam composites are enhanced by a strong interfacial bonding between the HGM filler and the polymer matrix. They are known to possess good impact behavior, low density, excellent compressive, flexural, hydrostatic, corrosive and tensile strength $[5,6,8-$ 16]. The attention of scholars has recently been drawn to its functionality and usage due to its low moisture absorption, good energy absorption, low weight and high specific strength which has made it applicable to most construction, transportation, machinery and aerospace industries [1720]. Also, hollow glass microsphere syntactic foams are good material for electronic purposes because of their excellent dielectric constant [Dinesh Pinisetty], their excellent temperature resistance nature makes them suitable for

¿ Open Access. () 2021 0. A. Afolabi et al., published by De Gruyter. (Cc) BY 4.0 License 
buoyancy materials such as in the deep sea exploration or underwater resistance operation [21], they equally possess good heat-resistance ability when mixed with an inorganic adhesive binder matrix which is applicable for the nose cap of NASA/Marshall Space Flight [22], likewise, they can be suitable for high-temperature materials that are lightweight in nature for structural purposes [23].

One of the important parameters that are not properly studied in HGM filled syntactic foam composites is void content. Void content in HGM foam composites plays a very important role on the tensile and dynamic properties. Even at $2.5 \%$ increased in void content could reduce the tensile and DMA properties by $15-20 \%$. Maximizing the void content in HGM syntactic foam composites is important as the HGM itself is a hollow void structure. Therefore the presence of void in composite further completes and induces and induce detrimental properties. The literature study also shows that HGM filled foam composites resulted in up to $10 \%$ void content, in addition of inherent HGM void. Most of the voids occurred during composite processing resulting in poor tensile strength. Therefore, a more efficient way of reducing the void content in the processing method of syntactic foam was adopted in this present work as the main area of interest. This study focusses on reducing the void content by a modified resin casting method. In this method, a degassing procedure is introduced as an intermediate processing step to eliminate voids before using of epoxy resin which resulted in good mechanical and thermal properties of the syntactic foam which is the novelty of the study. Additionally, the resultant composite was tested for density (experimental and theoretical), tensile and DMA properties and were discussed.

\section{Experimental procedures}

\subsection{Materials}

Epoxy resin LR 20 and hardener LR 281 were purchased from AMT composites, South Africa. The Hollow Glass Microballoons (HGM-T60) filler was procured from Anhui Elite Industrial Cop, Limited, Hong Kong Elite Industrial Group Limited, China (T60 trade name). The density of the HGM is $0.6 \mathrm{~g} / \mathrm{cm}^{3}$ with $10-60 \mu \mathrm{m}$ particle sizes.

\subsection{Processing}

The processing for the fabrication of epoxy resin (EP) / HGM filled foam composites (EPT60) was carried out in two steps:

\section{Step 1: Mixing and Degassing}

Syntactic foam composites were fabricated by mixing (mechanically) epoxy resin and the desired volume fraction of hollow glass microspheres in a glass beaker. The mixture was thoroughly stirred for $30 \mathrm{~min}$ to obtain uniform slurry and a homogenous solution in order to reduce agglomeration. The viscosity of the matrix (epoxy resin) was lowered by heating it up to $60^{\circ} \mathrm{C}$ for 1 hour. Thereafter, hardener was gently added to it and mixed thoroughly. During mechanical mixing of composites, air bubbles were entrapped which led to open cell structure porosity called voids [24]. The epoxy-resin and hardener ratio were 10:3 and hollow glass microsphere volume fraction was added for each sample preparation. The volume fraction of hollow glass microspheres was varied from 5 to $25 \%$.

\section{Step II: Curing}

This mixture was cast in the silicon mold made from mold max "30-part A" and mold max "30 STD catalyst part B" purchased from AMT composites as well. Silicon grease was used to coat the mold surfaces to ensure easy removal of syntactic foam slab after curing. The syntactic foam slab was cured at room temperature $\left(27^{\circ} \mathrm{C}\right)$ for 24 hours and then post cured at $80 \pm 5^{\circ} \mathrm{C}$ for $4 \mathrm{~h}$. Tensile test specimens were cut from the cured slabs using a fixed bench blade tile saw.

\subsection{SEM, TEM and DMA}

Scanning Electron Microscopy (SEM) was used to investigate the fracture surfaces and morphology of the syntactic foam composites. The fractured tensile and flexural specimens were examined using a Zeiss EVO 1 HD 15 Oxford instrument X-max scanning electron microscope (SEM). The specimens were gold coated before the SEM was conducted because the syntactic foams are not conductive and there is need for the flow of electron for the fracture images to be seen properly, this was done by Quorum Q150R ES machine for 6 minutes. The Transmission Electron Microscopy (TEM) was conducted using higher resolution (HR-TEM) Joel 2100, from Japan.

The Thermogravimetric Analysis TA (Model Q800 V20.6) instrument was used to perform the Dynamic Mechanical Analysis of the syntactic foam composites. The specimens used were measured according to ASTM D4065 standard $56 \mathrm{~mm} \times 12 \mathrm{~mm} \times 3 \mathrm{~mm}$ in length, width and thickness respectively. The tests were run in a 3-point bending mode on a support span length of $50 \mathrm{~mm}$ with heating temperature ranging from $20^{\circ} \mathrm{C}$ to $200^{\circ} \mathrm{C}$ at a frequency of $10 \mathrm{~Hz}$, rate of $3^{\circ} \mathrm{C} / \mathrm{min}$ and amplitude of $20 \mu \mathrm{m}$. Minimum tempera- 
ture lag occurred between the sample and the furnace environment as a result of maintaining the parameters throughout the test.

\subsection{Tensile Testing, and Density measurement}

Specimens for tensile and flexural properties were prepared in accordance to ASTM D 3039 and ASTM D790-02 test standard specifications respectively. MTS 793 servo-hydraulic machine with a load cell of $100 \mathrm{KN}$ and a test speed of 2 $\mathrm{mm} / \mathrm{min}$ was used. The length, width and thickness for the tensile samples were $250 \mathrm{~mm} \times 25 \mathrm{~mm} \times 3 \mathrm{~mm}$ respectively. Five specimens were tested from each syntactic foam sample and their mean values were used to calculate the final results.

\section{Results and Discussion}

\subsection{Structures and Morphology}

\subsubsection{Scanning Electron Microscopy (SEM)}

Figure $1(a$ and $b$ ) shows the nature of the HGM and structure under scanning electron microscopy (SEM) at different magnifications. Different sizes of the HGM were seen through the microscopy ranging from $10 \mu \mathrm{m}$ to $60 \mu \mathrm{m}$. The image output was adjusted by using gold to sputter the surface before the scanning process. The effect of these sizes

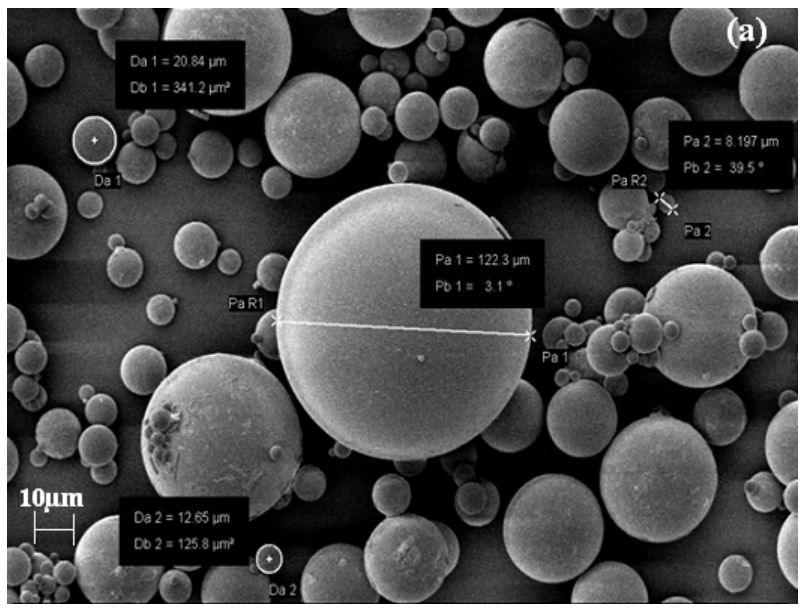

(a) was seen during the mixture with matrix resin at various percentage concentrations (5\%-25\%) designated as $(0.5 \%$ 2.5\%) in the TEM and SEM images.

\subsubsection{Transmission Electron Microscopy (TEM)}

The distribution of HGM sizes inside matrix resin was further investigated using transmission electron microscopy (TEM). The TEM images in Figure 2 (a-e) represent the distribution of HGM in the epoxy resin at different specifications. There was an uneven distribution of HGM filler in the matrix resin as the concentration increases from $5 \%$ to $25 \%$, which affected the mechanical properties of the syntactic foam composites and contributed to an increase in the porosity level of the EPT60 syntactic foam composites. Figure 2 (a and $b$ ) shows little or no agglomeration of the HGM due to lower concentration. The agglomeration increased as the concentration increased as seen in Figure 2 (c-e) with much clustering and percolation of HGM at 25\% (Figure 2e).

\subsection{Density and Void Measurement of Syntactic Foam Composite}

Based on the rule of mixture, the theoretical density values for HGM filled syntactic foam composites can be obtained. Theoretical density values are calculated using equation (1), while measured density was determined using ASTM C27194 , with specimen specification of $25 \times 25 \times 12.5 \mathrm{~mm}^{3}$. Three specimens each were cut and measured accordingly with the mean value recorded. The value for the void volume

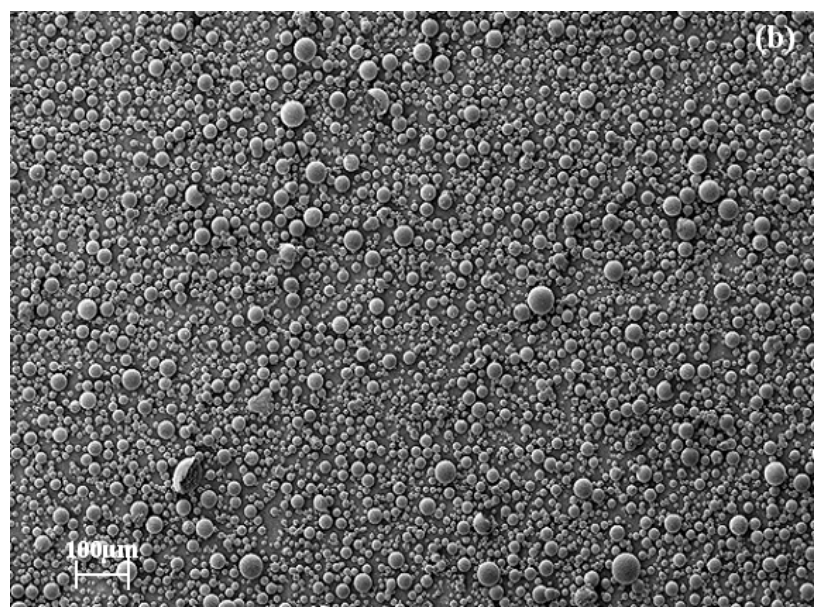

(b)

Figure 1: Microstructure of Hollow Glass Microsphere: (a) and (b) are Scanning Electron Microscopy (SEM) images showing different magnification of HGM at $10 \mu \mathrm{m}$ and $100 \mu \mathrm{m}$ respectively. 


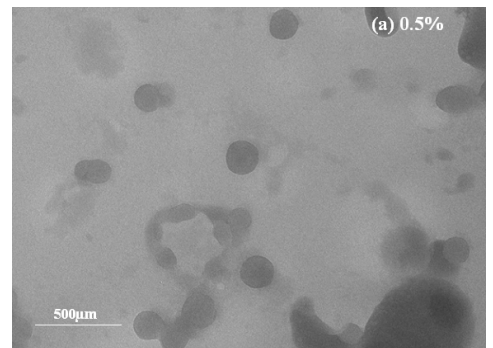

(a) $0.5 \%$

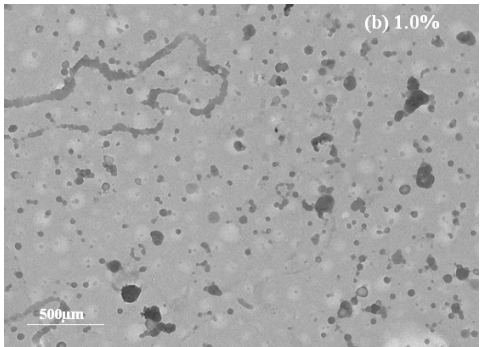

(b) $1.0 \%$

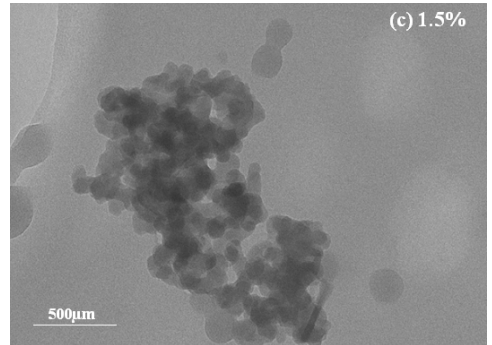

(c) $1.5 \%$

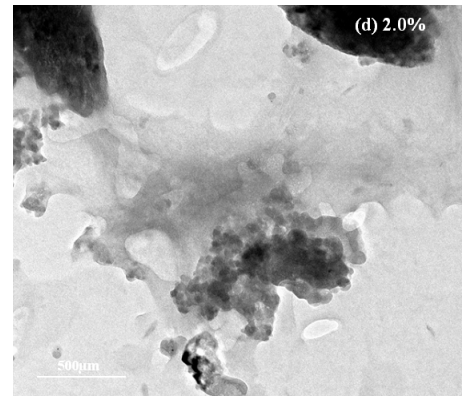

(d) $2.0 \%$

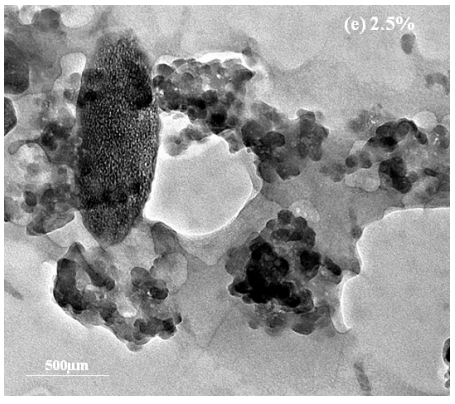

(e) $2.5 \%$

Figure 2: Transmission electron microscopy (TEM) images showing the clustered particles of the hollow glass microspheres dispersed in the syntactic foam composite at each volume fraction.

fraction also known as matrix porosity was calculated by estimating the difference between the theoretical density $\left(\rho_{t}\right)$ and the measured density $\left(\rho_{m}\right)$ using equation (1).

$$
\delta=\frac{\rho_{t}-\rho_{m}}{\rho_{t}} \cdot 100
$$

The theoretical density $\left(\rho_{t}\right)$, the measured density $\rho_{m}$ and the void volume fraction $(\delta)$ are presented in Table 1 . The density of the EPT60 syntactic foam composite increases compared with the HGM filler due to proper interaction between the constituent elements but shows decreasing values for both measured and theoretical densities as the HGM volume fraction increases. This corresponds to the report of Yingjie et al. [25] where the values of the measured and theoretical densities decrease with increasing HGM content. The measured densities were found to be lower than the theoretical densities [25-28] for all the weight fractions of HGM. Void fraction and HGM porosities have been studied to be undesired and should be kept to the minimum level because its presence can lead to modulus and strength reduction in syntactic foams [29]. The void fraction which is higher than the measured and theoretical densities of the syntactic foams can also be responsible for an increase in moisture absorption of the syntactic foam composites $[17,30]$ which can cause diffusion in the foam specimen structure and get accumulated in the matrix porosity region.

Table 1 shows the values of the measured densities and theoretical densities as it relates to the void fraction in the syntactic foam filled with HGM composites. The void fraction increased with an increase in the filler content,

Table 1: The density and porosity (void) values of syntactic foam composites.

\begin{tabular}{ccccc}
\hline Specimen name & Volume fraction of HGM $(\%)$ & \multicolumn{2}{c}{ Density of the composite $\left(\mathrm{g} / \mathrm{cm}^{3}\right)$} & Void fraction of Composite $(\%)$ \\
\cline { 2 - 4 } & & Theoretical & Measured & \\
\hline EPT60-1 & 0 & 1.150 & 1.120 & 2.61 \\
EPT60-2 & 5 & 1.145 & 1.122 & 2.01 \\
EPT60-3 & 10 & 1.140 & 1.110 & 2.63 \\
EPT60-4 & 15 & 1.135 & 1.105 & 2.64 \\
EPT60-5 & 20 & 1.131 & 1.096 & 3.09 \\
EPT60-6 & 25 & 1.126 & 1.075 & 4.53 \\
\hline
\end{tabular}


Table 2: Comparison of density and porosity (void) values of syntactic foam composites based on the present work and existing literatures.

\begin{tabular}{|c|c|c|c|c|c|c|}
\hline S/no & Matrix type & $\begin{array}{l}\text { Composition of } \\
\text { HGM and type }\end{array}$ & $\begin{array}{c}\text { Theoretical } \\
\text { density }\left(\rho_{t}\right) \\
\left(\mathrm{g} / \mathrm{cm}^{3}\right)\end{array}$ & $\begin{array}{c}\text { Measured } \\
\text { density }\left(\rho_{m}\right) \\
\left(\mathrm{g} / \mathrm{cm}^{3}\right)\end{array}$ & $\begin{array}{c}\text { Void } \\
\text { fraction } \delta \\
(\%)\end{array}$ & Reference \\
\hline 1 & Epoxy resin LR20 & - & 1.150 & 1.120 & 2.61 & Present work \\
\hline 2 & Epoxy resin LR20 & $5 \%$ HGM-T60 & 1.145 & 1.122 & 2.01 & \\
\hline 3 & Epoxy resin LR20 & $10 \%$ HGM-T60 & 1.140 & 1.110 & 2.63 & \\
\hline 4 & Epoxy resin LR20 & $15 \%$ HGM-T60 & 1.135 & 1.105 & 2.64 & \\
\hline 5 & Epoxy resin LR20 & $20 \%$ HGM-T60 & 1.131 & 1.096 & 3.09 & \\
\hline 6 & Epoxy resin LR20 & $25 \%$ HGM-T60 & 1.126 & 1.075 & 4.53 & \\
\hline 7 & Vinyl ester VE & - & 0.116 & - & - & [33] \\
\hline 8 & Vinyl ester VE & $30 \%$ HGM-K46 & 0.951 & 0.905 & 4.8 & \\
\hline 9 & Vinyl ester VE & $40 \%$ HGM-K46 & 0.881 & 0.798 & 9.3 & \\
\hline 10 & Vinyl ester VE & $50 \%$ HGM-K46 & 0.811 & 0.811 & 0.0 & \\
\hline 11 & Vinyl ester VE & $60 \%$ HGM-K46 & 0.740 & 0.655 & 11.4 & \\
\hline 12 & Epoxy resin E51 & $47 \%$ HGM-S38 & 0.593 & 0.536 & 9.6 & {$[25]$} \\
\hline 13 & Epoxy resin E51 & $49 \%$ HGM-S38 & 0.580 & 0.522 & 10.0 & \\
\hline 14 & Epoxy resin E51 & $51 \%$ HGM-S38 & 0.569 & 0.509 & 10.5 & \\
\hline 15 & Epoxy resin E51 & $53 \%$ HGM-S38 & 0.558 & 0.498 & 10.7 & \\
\hline 16 & Epoxy resin E51 & $55 \%$ HGM-S38 & 0.547 & 0.488 & 10.8 & \\
\hline 17 & Epoxy resin E51 & $57 \%$ HGM-S38 & 0.536 & 0.474 & 11.6 & \\
\hline 18 & Epoxy resin DER 332 & - & 1.165 & 1.160 & 0.4 & [34] \\
\hline 19 & Epoxy resin DER 332 & $30 \%$ HGM-S22 & 0.881 & 0.884 & 0 & \\
\hline 20 & Epoxy resin DER 332 & $50 \%$ HGM-S 22 & 0.692 & 0.656 & 5.3 & \\
\hline 21 & Epoxy resin DER 332 & $30 \%$ HGM-K46 & 0.953 & 0.918 & 3.6 & \\
\hline 22 & Epoxy resin DER 332 & $50 \%$ HGM-K46 & 0.812 & 0.823 & 0 & \\
\hline 23 & $\begin{array}{c}\text { Epoxy resin Epon } \\
8008 \& 1031\end{array}$ & $10 \%$ HGM- S60 & 1.275 & 1.240 & 2.71 & {$[31]$} \\
\hline 24 & $\begin{array}{l}\text { Epoxy resin Epon } \\
8008 \& 1031\end{array}$ & $20 \%$ HGM-S60 & 1.216 & 1.180 & 2.96 & \\
\hline 25 & $\begin{array}{l}\text { Epoxy resin Epon } \\
8008 \& 1031\end{array}$ & $30 \%$ HGM-S60 & 1.153 & 1.112 & 3.56 & \\
\hline 26 & $\begin{array}{l}\text { Epoxy resin Epon } \\
8008 \& 1031\end{array}$ & $40 \%$ HGM-S60 & 1.087 & 1.056 & 2.85 & \\
\hline 27 & $\begin{array}{l}\text { Epoxy resin Epon } \\
8008 \& 1031\end{array}$ & $50 \%$ HGM-S60 & 1.017 & 0.985 & 3.15 & \\
\hline 28 & $\begin{array}{l}\text { Epoxy resin Epon } \\
8008 \& 1031\end{array}$ & $60 \%$ HGM-S60 & 0.943 & 0.885 & 6.15 & \\
\hline
\end{tabular}

Figure 2(c-d). The more the concentration of the HGM content, the more the void volume fraction. The void volume fraction changes from $2.6 \%$ at EPT60-1 to $4.53 \%$ at EPT60-6 of the syntactic foam. This corresponds to an earlier report by Zhu et al. [31] where the void content also increased with an increasing volume fraction of HGM, which is as a result of surface infiltration between the matrix and the filler content. Also, it was an indication that there are heterogeneity and entrapment of air bubbles during the mechanical mixing of the constituent elements [32]. Comparison between densities of the present work and some existing literature was also reported in Table 2.

Table 2 relates the void fraction of the present work with some existing literature, the void fraction value reduced compared to most previous works due to the degassing method used in its processing but increased with increasing HGM volume fraction [25, 31]. This is as a result of good dispersion and adhesion of HGM filler in the matrix resin and smaller volume fraction of HGM used. 

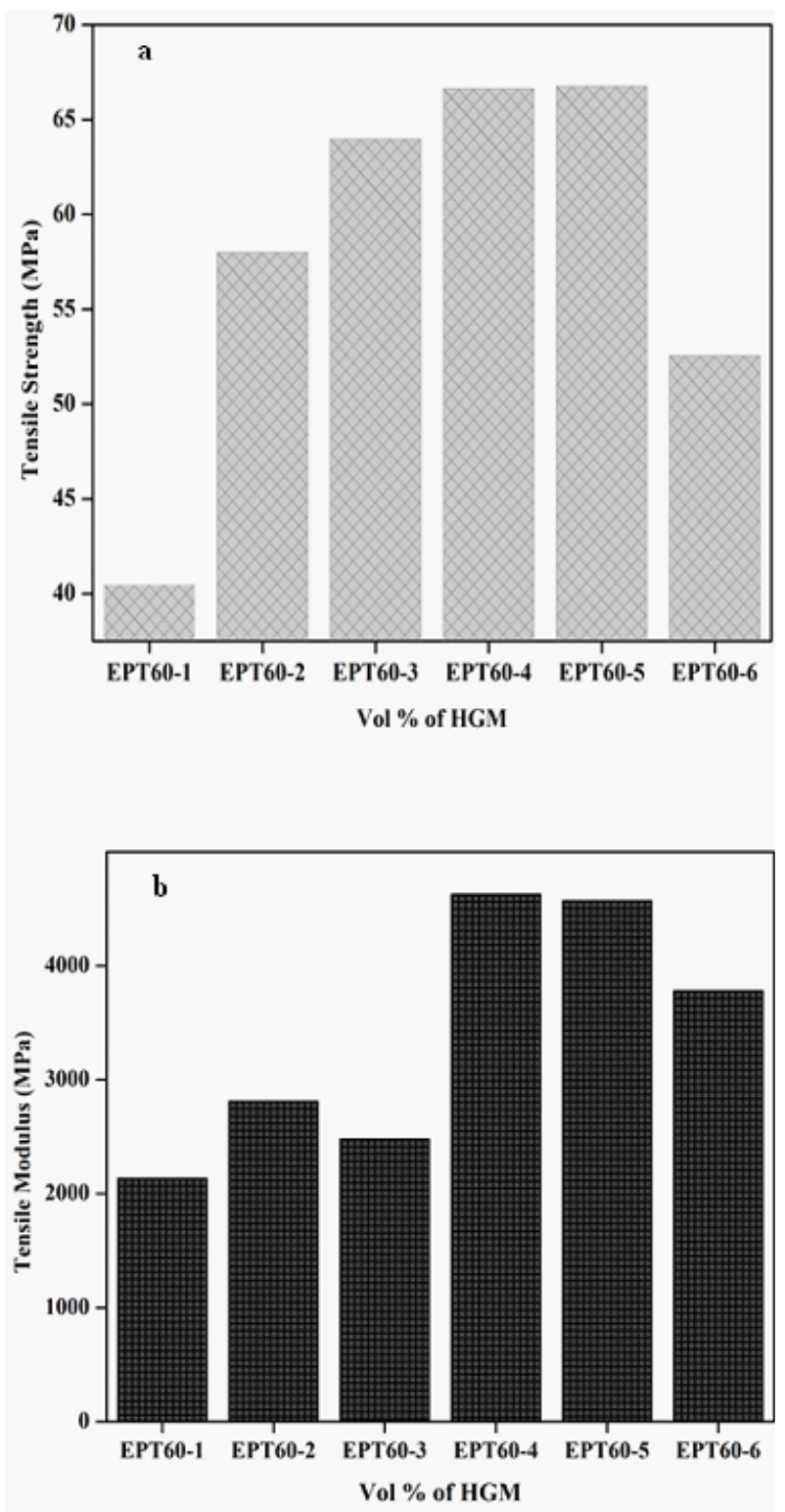

Figure 3: a) Tensile strength relationship between the neat epoxy resin and EPT60 syntactic foam and b) Tensile modulus relationship between the neat epoxy resin and EPT60 syntactic foam.

\subsection{Tensile properties}

The tensile properties of the EPT60 syntactic foam composites are shown in Figure 3 and Table 3. Figures $3 a$ and 3b, report the tensile strength and modulus relationship between the neat resin epoxyand the EPT60 syntactic foam respectively. With the addition of HGM, tensile strength and modulus increased at varying percentage volume fractions, highest tensile strength was at EPT60-5 (66.7 MPa), which is an increase of about $65 \%$ compared to the neat epoxy resin and highest tensile modulus at EPT60-4 (4.5 GPa). The tensile strength of syntactic foam increased consistently with an increase in the HGM content until EPT60-5 which correspond to the report by Nityanshu et al. and Rupan et $a l$. where tensile strength of the Polypropylene increased upon the inclusion of HGM as a result of improved interfacial adhesion with the matrix $[15,16]$ before it declined at EPT60-6 due to increased void content caused by the agglomeration and reduced resin content resulting in low bonding and load transfer stability between the filler and the resin as shown in Figure 3a. The interfacial strength between the microsphere and the matrix is very important for the syntactic foam composites as it affects its overall tensile strength. Although, some previous studies [28, 32] reported a decline in the tensile strength by $60-80 \%$ as compared to neat epoxy. They stated that the increase in HGM volume fraction reduced the tensile strength because as the volume fraction of the epoxy resin in the material decreased, the strength of the composites also decreased due to higher range of microballoons in the composites structure. It was however observed that the tensile modulus at EPT60-3 decline as a result of high agglomeration (Figure $2 \mathrm{c}$ and $3 \mathrm{~b}$ ) between the filler and the matrix as a result of mixing which caused an early brittle failure at that point. The increase in modulus of EPT60 syntactic foam composites over that of neat epoxy resin confirms the report of Gupta et al. [35] that the syntactic foam has a higher Young's modulus in several compositions than the neat

Table 3: Tensile strength of syntactic foam composites.

\begin{tabular}{lccccccc}
\hline Materials & Volume fraction & \multicolumn{2}{c}{ Tensile Modulus } & \multicolumn{2}{c}{ Tensile Strength } & \multicolumn{2}{c}{ Tensile Strain } \\
\cline { 2 - 7 } & HGM (\%) & MPa & \% increase & MPa & \% increase & (mm/mm) & \% increase \\
\hline EPT60-1 & 0 & 2135 & 0 & 40.47 & 0 & 0.0297 & 0 \\
EPT60-2 & 5 & 2813 & 31.76 & 57.97 & 43.24 & 0.0409 & 37.71 \\
EPT60-3 & 10 & 2480 & 16.16 & 63.97 & 58.07 & 0.0277 & -6.73 \\
EPT60-4 & 15 & 4628 & 116.77 & 66.60 & 64.57 & 0.0219 & -26.26 \\
EPT60-5 & 20 & 4570 & 114.05 & 66.73 & 64.89 & 0.0256 & -13.80 \\
EPT60-6 & 25 & 3782 & 77.14 & 52.55 & 29.85 & 0.0217 & -26.94 \\
\hline
\end{tabular}


Table 4: Comparison of tensile properties of syntactic foam based on present work and existing literatures.

\begin{tabular}{|c|c|c|c|c|c|}
\hline S/no & Matrix type & $\begin{array}{l}\text { Composition of } \\
\text { HGM and type }\end{array}$ & $\begin{array}{l}\text { Tensile strength } \\
\qquad(\mathrm{MPa})\end{array}$ & $\begin{array}{l}\text { Tensile modulus } \\
\qquad(\mathrm{MPa})\end{array}$ & Reference \\
\hline 1 & Epoxy resin LR 20 & - & 40.47 & 2135 & Present work \\
\hline 2 & Epoxy resin LR 20 & $5 \%$ HGM-T60 & 57.97 & 2813 & \\
\hline 3 & Epoxy resin LR 20 & $10 \%$ HGM-T60 & 63.97 & 2480 & \\
\hline 4 & Epoxy resin LR 20 & $15 \%$ HGM-T60 & 66.60 & 4628 & \\
\hline 5 & Epoxy resin LR 20 & $20 \%$ HGM-T60 & 66.73 & 4570 & \\
\hline 6 & Epoxy resin LR 20 & $25 \%$ HGM-T60 & 52.55 & 3782 & \\
\hline 7 & Polybutylene succinate & - & 34.7 & 330 & [36] \\
\hline 8 & Polybutylene succinate & $5 \%$ HGM-T60 & 32.2 & 355 & \\
\hline 9 & Polybutylene succinate & $10 \%$ HGM-T60 & 25.3 & 371 & \\
\hline 10 & Polybutylene succinate & $15 \%$ HGM-T60 & 23.7 & 439 & \\
\hline 11 & Polybutylene succinate & $20 \%$ HGM-T60 & 18.1 & 464 & \\
\hline 12 & Epoxy resin DER 332 & - & 57.2 & 2752 & [12] \\
\hline 13 & Epoxy resin DER 332 & $30 \%$ HGM- K46 & 25.1 & 3700 & \\
\hline 14 & Epoxy resin DER 332 & $40 \%$ HGM-K46 & 20.7 & 3641 & \\
\hline 15 & Epoxy resin DER 332 & $50 \%$ HGM-K46 & 15.6 & 3615 & \\
\hline 16 & Epoxy resin DER 332 & $60 \%$ HGM-K46 & 12.8 & 3491 & \\
\hline 17 & Epoxy resin DER 332 & - & 26.0 & 2700 & [34] \\
\hline 18 & Epoxy resin DER 332 & $30 \%$ HGM-S22 & 17.0 & 2200 & \\
\hline 19 & Epoxy resin DER 332 & $50 \%$ HGM-S22 & 16.5 & 2100 & \\
\hline 20 & Epoxy resin DER 332 & $30 \%$ HGM-K46 & 21.5 & 3200 & \\
\hline 21 & Epoxy resin DER 332 & $50 \%$ HGM-K46 & 23.0 & 4100 & \\
\hline 22 & $\begin{array}{c}\text { Acrylonitrile Butadiene } \\
\text { Styrene (ABS) }\end{array}$ & - & 29.5 & 1820 & [37] \\
\hline 23 & $\begin{array}{c}\text { Acrylonitrile Butadiene } \\
\text { Styrene (ABS) }\end{array}$ & $5 \%$ HGB-TK70 & 30.2 & 1840 & \\
\hline 24 & $\begin{array}{c}\text { Acrylonitrile Butadiene } \\
\text { Styrene (ABS) }\end{array}$ & $10 \%$ HGB-TK70 & 30.8 & 1860 & \\
\hline 25 & $\begin{array}{c}\text { Acrylonitrile Butadiene } \\
\text { Styrene (ABS) }\end{array}$ & $10 \%$ HGB-TK70 & 32.2 & 1875 & \\
\hline 26 & $\begin{array}{c}\text { Acrylonitrile Butadiene } \\
\text { Styrene (ABS) }\end{array}$ & $20 \%$ HGB-TK70 & 32.2 & 1900 & \\
\hline
\end{tabular}

The strain rate of the neat resin is substantially higher than that of the syntactic foam except for EPT60-2 with the lowest HGM volume fraction in the composites while that of other syntactic foam from EPT60-3 to 6 is lower than the neat epoxy. This resulted from their higher void content in the composites due to the larger percentage of HGM volume fraction.

Table 4 shows the compared tensile properties of the present work with some existing literature which observed that the tensile and modulus properties of the present work improved compared to the existing literature due to the degassing method of preparation and the small void fraction of the syntactic foam which resulted in good matrix/filler interaction. High volume fraction of HGM can result in ag- glomeration leading to low tensile strength and modulus in the syntactic foam composites [36]. Also a poor interfacial bond between the matrix and the microballoons resulting from a high-volume fraction of HGM used can be responsible for the reduction in tensile strength of the syntactic foam [28]. However, good interfacial adhesion between the matrix and HGM volume fraction in the syntactic foam was responsible for the increase in tensile strength in the present work as shown in Table 3. Meanwhile, Ji-Zhao Liang et al., Rupam et al., and Naresh and Siva [14, 16, 37] reported a similar result to the present work, where tensile strength increases with increase in filler concentration. The effect of the good interfacial adhesion between the matrix and 
the HGM was shown through the fracture mechanism in Figure 4.

\subsection{Fracture mechanism}

The fracture mechanism for the tensile test conducted on the syntactic foam composites as observed under SEM are shown in Figure 4(a-f) for all the volume fraction compositions respectively. Figure 4(a) shows the cracked portion for the plain epoxy resin composites where the crack could be seen freely propagating around the surfaces which are responsible for their brittle failure [38]. The cracked surfaces become clearer with the introduction of HGM as shown in Figure 4(b-f). The marked regions identified as "1"- deboned microspheres, "2"- fractured microspheres and " 3 "- fractured surfaces on the syntactic foam. The fractured microsphere and deboned microspheres increased with an increasing volume fraction of HGM in the syntactic foam composites which are as a result of good bonding effect on interfaces between the matrix resin and can also be attributed to good interaction between the matrix and the filler [38], that the micrographs of HGM/epoxy composite show a good interaction of HGM with the epoxy matrix.
Figure $4 \mathrm{~b}$ shows a little roughness on the fracture surface due to a reduced void volume fraction of the composites while much roughness could be seen from Figure 4(c-f) due to their higher void volume content in the syntactic foam which is also responsible for their low strain value compared to the neat resin, Table 3.

\subsection{Dynamic mechanical analysis (DMA)}

The dynamic mechanical analysis was conducted to study the viscoelastic properties of the syntactic foam composites. The storage, and loss modulus values for the EPT60 syntactic foam composites and neat epoxy matrix were taken from three different temperatures measurement $30^{\circ} \mathrm{C}, 50^{\circ} \mathrm{C}$ and $60^{\circ} \mathrm{C}$ as shown in Table 5. Figures $5(\mathrm{a}-\mathrm{c})$ show the storage modulus, loss modulus and tan delta versus temperature graphs of the syntactic foam composites. At the temperature of $30^{\circ} \mathrm{C}$, the storage modulus does not show a consistent trend but a decrease in loss modulus was observed as the HGM increases. At $50^{\circ} \mathrm{C}$ temperature, storage modulus increased while loss modulus decreased with respect to neat resin. At $60^{\circ} \mathrm{C}$, both the storage and loss modulus increased at the addition of HGM with respect to neat resin. The maxi-

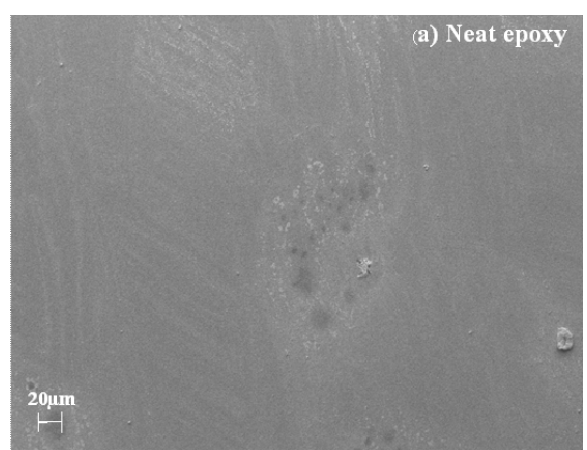

(a)

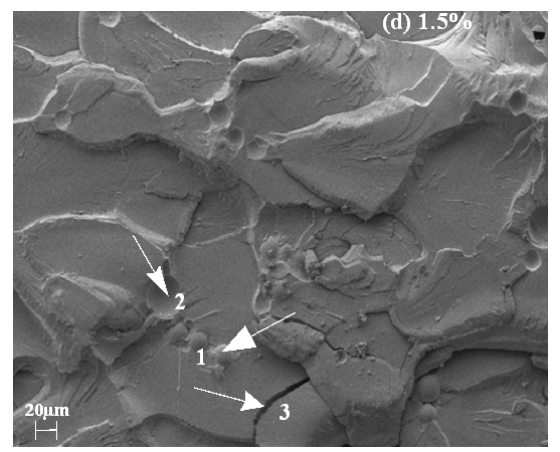

(d)

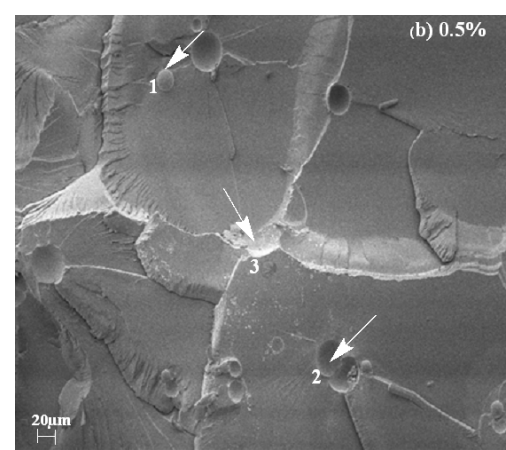

(b)

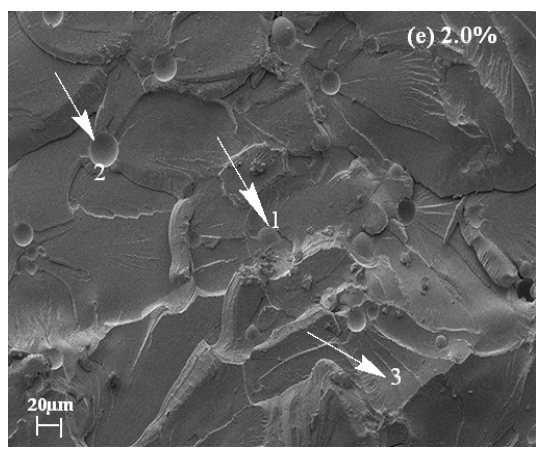

(e)

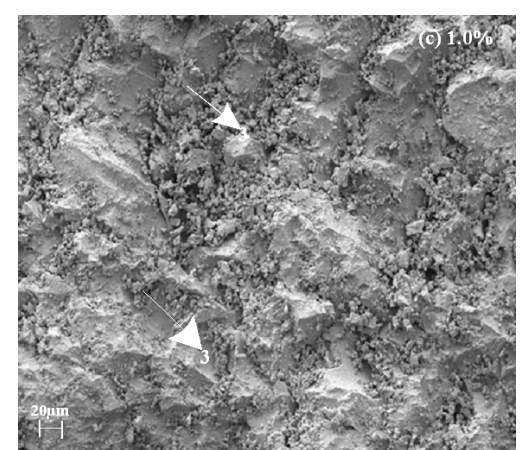

(c)

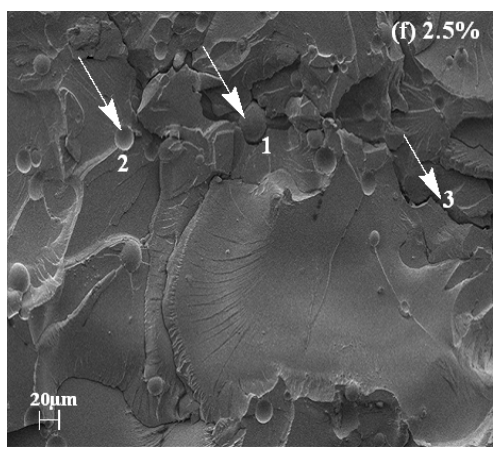

(f)

Figure 4: SEM images for tensile fracture surfaces for (a) neat resin and (b-f) percentage fraction of HGM 0.5-2.5\% in syntactic foam at 500 magnifications showing the arrowed areas as 1: deboned microspheres, 2: fractured microspheres and 3: fractured surfaces. 
mum storage modulus values were at EPT60-6 for the three selected temperatures which are 2705, 2447, and $1466 \mathrm{MPa}$ respectively and the loss modulus was highest at $60^{\circ} \mathrm{C}$ of EPT60-6 (261.5 MPa). The improved storage and loss modulus values compared to neat resin can be attributed to good interaction and interfacial bonding between the microsphere and the matrix and also as a result of the lower density and void content. The storage modulus decreased with increased temperature due to the reduction in the void rate of the composites as a result of the degassing method in processing it which correlates with earlier reports from
Sankaran et al. [1] and Ghamsari et al. [3] while John B et al. [39] reported a sudden decrease in the storage modulus of cyanate ether syntactic foam composites with temperature.

The loss modulus shows the variation in values but increases mostly with the addition of HGM in the EPT60 syntactic foam. The maximum loss modulus for neat epoxy matrix resin was $223 \mathrm{MPa}$ at $50^{\circ} \mathrm{C}$ and $\sim 262 \mathrm{MPa}$ at $60^{\circ} \mathrm{C}$ for EPT60-6. This shows that the loss modulus of syntactic foam was noticeably affected as the percentage of HGM

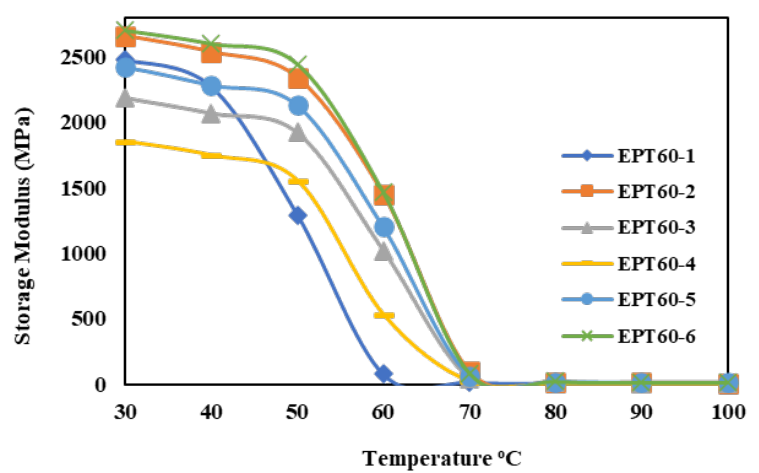

(a)

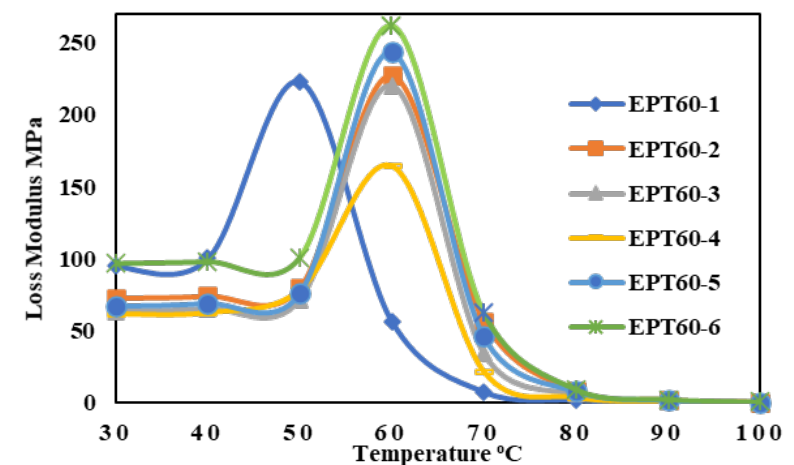

(b)

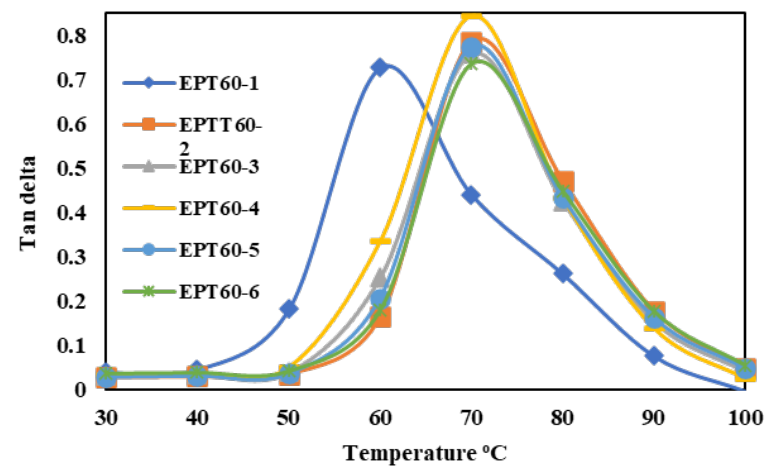

(c)

Figure 5: (a) Storage modulus, (b) loss modulus and (c) tan delta of HGMSF and neat epoxy matrix against temperature.

Table 5: Comparison of storage modulus (SMD) and loss modulus (LMD) values of HGMSF composites and neat epoxy matrix resin.

\begin{tabular}{|c|c|c|c|c|c|c|c|}
\hline \multirow{3}{*}{$\begin{array}{l}\text { Specimen } \\
\text { name }\end{array}$} & \multirow[t]{3}{*}{ Volume fraction of HGM (\%) } & \multicolumn{6}{|c|}{ Temperature $\left({ }^{\circ} \mathrm{C}\right)$} \\
\hline & & \multicolumn{2}{|c|}{30} & \multicolumn{2}{|c|}{50} & \multicolumn{2}{|r|}{60} \\
\hline & & SMD & LMD & SMD & LMD & SMD & LMD \\
\hline EPT60-1 & 0 & 2478 & 94.78 & 1294 & 223.2 & 77.62 & 56.63 \\
\hline ЕРT60-2 & 5 & 2663 & 72.63 & 2343 & 79.9 & 1449 & 227.2 \\
\hline ЕРT60-3 & 10 & 2190 & 63.84 & 1924 & 71.76 & 1022 & 220.2 \\
\hline ЕРT60-4 & 15 & 1854 & 62.09 & 1555 & 78.63 & 535.4 & 164.6 \\
\hline EPT60-5 & 20 & 2426 & 67.48 & 2136 & 75.93 & 1203 & 243.5 \\
\hline EPT60-6 & 25 & 2705 & 96.74 & 2447 & 101 & 1466 & 261.5 \\
\hline
\end{tabular}


Table 6: Comparison of $\tan \delta$ values of HGMSF and neat epoxy resin at different temperature range.

\begin{tabular}{ccccc}
\hline Specimen name & Volume fraction of HGM (\%) & \multicolumn{3}{c}{ Temperature } \\
\cline { 3 - 4 } & & $30^{\circ} \mathrm{C}$ & $60^{\circ} \mathrm{C}$ & $70^{\circ} \mathrm{C}$ \\
\hline EPT60-1 & 0 & 0.03824 & 0.7259 & 0.4391 \\
EPT60-2 & 5 & 0.02727 & 0.1637 & 0.7851 \\
EPT60-3 & 10 & 0.02915 & 0.2518 & 0.7569 \\
EPT60-4 & 15 & 0.03349 & 0.3349 & 0.8435 \\
EPT60-5 & 20 & 0.02713 & 0.2055 & 0.7727 \\
EPT60-6 & 25 & 0.03576 & 0.1793 & 0.7354 \\
\hline
\end{tabular}

increases and it reflects either retention or a marginal increase till the maximum temperature was reached.

The storage modulus ( $\mathrm{E}^{\prime}$ ) of the EPT60 syntactic foam composite measures the stored energy in the elastic portion of the composite as shown in Figure 5a. However, the loss modulus $\left(\mathrm{E}^{\prime \prime}\right)$ of the EPT60 syntactic foam composite measures the energy dissipated at heat per cycle under deformation of the material as shown in Figure $4 \mathrm{~b}$.

\subsubsection{Damping Coefficient}

The values for the damping coefficient or loss factor $\tan \delta$ which is the measure of how efficient the syntactic foam loses energy to molecular rearrangement and internal friction as compared to the neat epoxy resin was varied at different temperatures " $30^{\circ} \mathrm{C}, 60^{\circ} \mathrm{C}$ and $70^{\circ} \mathrm{C}$ " as reported in Table 6. The glass transition temperature $\left(\mathrm{T}_{g}\right)$ was at $70^{\circ} \mathrm{C}$ which was the temperature at which the EPT60 syntactic foam reaches its maximum $\tan \delta$ as shown in Figure 5c. The inclusion of HGM reduced the peak of epoxy resin tan $\delta$ which is an indication of good interfacial bonding. This shows that when the constituents material of the composites exhibit good interfacial bonding, it resulted in less energy dissipation resulting in a lower value of $\tan \delta$ [3]. It also shows that epoxy resin exhibited a rubbery plateau before the EPT60 syntactic foam which was an indication of proper dispersion of HGM in the epoxy resin. In addition, the decrease in $\mathrm{T}_{g}$ with the addition of HGM resulted in the plasticization of the epoxy resin which can be linked to the reduced void fraction in the composites as a result of the degasing method [40]. Therefore, an increase in the interfacial interaction between the matrix and HGM leads to a decrease in the loss factor ( $\tan \delta$ ) of EPT60 syntactic foam composites and also improves the damping performance of the molecule motion in the foam composites [40, 41].

\section{Conclusion}

Syntactic foam composites prepared by degassing method with a varied volume fraction of HGM from $5-25 \%$ were prepared. The effect of varying compositions of HGM on the mechanical and dynamic mechanical properties was investigated. The tensile properties from the test revealed an improved strength as the volume fraction of HGM increased due to good interfacial adhesion between the filler and the matrix and the low void content in the composites due to degassing method of processing. The dynamic mechanical analysis of the syntactic foam composites showed a decrease in storage modulus and an increase in loss modulus with increasing temperature with the maximum value of storage modulus of $2705 \mathrm{MPa}$ at $30^{\circ} \mathrm{C}$ and maximum loss modulus of $\sim 262$ at $60^{\circ} \mathrm{C}$. The damping performance also reduces due to the reduction in the intensity of the tan delta peak due to good interfacial interaction between the molecules of the polymer and the HGM. The density of syntactic foam composites declined gradually as the volume fraction of HGM increased. In addition, this study shows that the properties of syntactic foam composite can be effectively controlled by reducing the void content when changing the volume fraction of HGM embedded in the matrix. The syntactic foam composite can be regarded as lightweight materials for structural application and in the context of the search for materials with better tensile properties for aerospace, marine, automobile and other design fields, this work contributes to our understanding of improving the properties of syntactic foam.

Conflict of Interests: The authors declare no conflict of interest regarding this manuscript.

Acknowledgement: The authors would like to appreciate the support gotten from the DST-CSIR U-295 grant and Durban University of Technology for the opportunity given to conduct this research work. 


\section{References}

[1] Sankaran, S., et al., Characterization of epoxy syntactic foams by dynamic mechanical analysis. Journal of Materials Science, 2006. 41(13): p. 4041-4046.

[2] Le, V.S., et al., Mechanical properties of geopolymer foam at high temperature. Science and Engineering of Composite Materials, 2020. 27(1): p. 129-138.

[3] Ghamsari, A.K., E. Zegeye, and E. Woldesenbet, Viscoelastic properties of syntactic foam reinforced with short sisal fibers. Journal of Composite Materials, 2013. 49(1): p. 27-34.

[4] Panteghini, A. and L. Bardella, On the compressive strength of glass microballoons-based syntactic foams. Mechanics of Materials, 2015. 82: p. 63-77.

[5] Wouterson, E.M., et al., Specific properties and fracture toughness of syntactic foam: Effect of foam microstructures. Composites Science and Technology, 2005. 65(11-12): p. 1840-1850.

[6] Doddamani, M., et al., Compressive and flexural properties of functionally graded fly ash cenosphere-epoxy resin syntactic foams. Polymer Composites, 2015. 36(4): p. 685-693.

[7] Gogoi, R., et al., Effect of Hollow Glass Microspheres on the Morphology, Rheology and Crystallinity of Short Bamboo FiberReinforced Hybrid Polypropylene Composite. Jom, 2018. 71(2): p. 548-558.

[8] Gupta, N., E. Woldesenbet, and P. Mensah, Compression properties of syntactic foams: effect of cenosphere radius ratio and specimen aspect ratio. Composites Part A: Applied Science and Manufacturing, 2004. 35(1): p. 103-111.

[9] Shutov FA, K.D., Frisch KC, editor, Syntactic polymeric foams. In: Handbook of polymeric foams and foam technology. New York: Hanser Publishers, 1991: p. p. 355-74.

[10] Bunn, P. and J. Mottram, Manufacture and compression properties of syntactic foams. Composites, 1993. 24(7): p. 565-571.

[11] Woldensenbet, E. and N. Sankella, Flexural properties of nanoclay syntactic foam sandwich structures. J Journal of Sandwich Structures Materials \& Design, 2009. 11(5): p. 425-444.

[12] Gupta, N. and E. Woldesenbet, Characterization of flexural properties of syntactic foam core sandwich composites and effect of density variation. Journal of composite materials, 2005. 39(24): p. 2197-2212.

[13] Fine, T., H. Sautereau, and V. Sauvant-Moynot, Innovative processing and mechanical properties of high temperature syntactic foams based on a thermoplastic/thermoset matrix. Journal of materials science, 2003. 38(12): p. 2709-2716.

[14] Mallireddy, N. and K. Siva, Investigation of Microstructural, Mechanical and Corrosion Properties of AA7010-TiB2 in-situ Metal Matrix Composite. Science and Engineering of Composite Materials, 2020. 27(1): p. 97-107.

[15] Nityanshu Kumar a, S.M.a., 1, Vinay Khandelwal a, 1, Byravan Arun b, Gaurav Manik, Light-weight high-strength hollow glass microspheres and bamboo fiber based hybrid polypropylene composite: A strength analysis and morphological study Composite Part B:, 2017. 109: p. 9.

[16] Rupam Gogoi , G.M., Byravan Arun, High specific strength hybrid polypropylene composites using carbon fibre and hollow glass microspheres: Development, characterization and comparison with empirical models. Composite Part B:, 2019. 173.

[17] Gupta, N. and E. Woldesenbet, Hygrothermal studies on syntactic foams and compressive strength determination. Composite
Structures, 2003. 61(4): p. 311-320.

[18] Kim Ho Sung ., M.A.K., Fracture and Impact Behaviour of Hollow Micro-sphere-Epoxy Resin Composites. Composite Part A: Applied Science and Manufacturing, 2001. 32: p. 1311-1317.

[19] Chawla, K., Foams, fibers, and composites: Where do we stand? Materials Science Engineering: A, 2012. 557: p. 2-9.

[20] Yu, W., H. Xue, and M. Qian, Tensile and compressive properties of epoxy syntactic foams reinforced by short glass fiber. Indian Journal of Engineering and material sciences, 2017. 24: p. 283 289.

[21] Ren, S., et al., Development of a buoyancy material of hollow glass microspheres/SiO2 for high-temperature application. Journal of Alloys and Compounds, 2017. 721: p. 213-219.

[22] Geng, H., et al., Fabrication of heat-resistant syntactic foams through binding hollow glass microspheres with phosphate adhesive. Materials \& Design, 2016. 95: p. 32-38.

[23] Sue Rena, b., d, Xin Taod, Xiaohui Mad, Jiachen Liud, Haiyan Dud, Anran Guod, Jun Xub,c, *, Jun Lianga, Shaohua Chena, Jingran Gea, ${ }^{\star}$, Fabrication of fly ash cenospheres-hollow glass microspheres/borosilicate glass composites for high temperature application. Ceramics International, 2018. 44: p. 1147-1155.

[24] Ashida K, A.H.L.E., Syntactic foam; Handbook of plastic foams: types, properties, manufacture and applications,. Noyes Publications, New Jersey, 1995: p. pp. 147-63.

[25] Qiao, Y., et al., Investigation of flexural properties of hollow glass microsphere filled resin-matrix composites. Pigment \& Resin Technology, 2016. 45(6): p. 426-430.

[26] Tagliavia, G., M. Porfiri, and N. Gupta, Influence of moisture absorption on flexural properties of syntactic foams. Composites Part B: Engineering, 2012. 43(2): p. 115-123.

[27] Yung, K., et al., Preparation and properties of hollow glass microsphere-filled epoxy-matrix composites. Composites Science and Technology, 2009. 69(2): p. 260-264.

[28] Gupta, N. and R. Nagorny, Tensile properties of glass microballoon-epoxy resin syntactic foams. Journal of Applied Polymer Science, 2006. 102(2): p. 1254-1261.

[29] Woldesenbet E., N.G., Jadhav, Effects of Density and Strain Rate on Properties of Syntactic Foam. journal of materials science, 2005. 40: p. 4009-4017.

[30] Koopman, M., et al., Microstructural failure modes in three-phase glass syntactic foams. Journal of Materials Science, 2006. 41(13): p. 4009-4014.

[31] Zhu, B., et al., Thermal, dielectric and compressive properties of hollow glass microsphere filled epoxy-matrix composites. Journal of Reinforced Plastics and Composites, 2012. 31(19): p. 1311 1326.

[32] Yu, M., P. Zhu, and Y. Ma, Experimental study and numerical prediction of tensile strength properties and failure modes of hollow spheres filled syntactic foams. Computational Materials Science, 2012. 63: p. 232-243.

[33] Tagliavia, G., M. Porfiri, and N. Gupta, Analysis of flexural properties of hollow-particle filled composites. Composites Part B: Engineering, 2010. 41(1): p. 86-93.

[34] Colloca, M., N. Gupta, and M. Porfiri, Tensile properties of carbon nanofiber reinforced multiscale syntactic foams. Composites Part B: Engineering, 2013. 44(1): p. 584-591.

[35] Gupta, N., R. Ye, and M. Porfiri, Comparison of tensile and compressive characteristics of vinyl ester/glass microballoon syntactic foams. Composites Part B: Engineering, 2010. 41(3): p. 236-245. 
[36] Li, J., X. Luo, and X. Lin, Preparation and characterization of hollow glass microsphere reinforced poly(butylene succinate) composites. Materials \& Design, 2013. 46: p. 902-909.

[37] Liang, J.-Z., Tensile and Flexural Properties of Hollow Glass Beadfilled ABS Composites. Journal of Elastomers \& Plastics, 2005. 37(4): p. 361-370.

[38] Imran, M., A. Rahaman, and S. Pal, Effect of low concentration hollow glass microspheres on mechanical and thermomechanical properties of epoxy composites. Polymer Composites, 2019. 40(9): p. 3493-3499.
[39] John, B., C.P.R. Nair, and K.N. Ninan, Effect of nanoclay on the mechanical, dynamic mechanical and thermal properties of cyanate ester syntactic foams. Materials Science and Engineering: A, 2010. 527(21-22): p. 5435-5443.

[40] Huang, C., et al., Mechanical and dynamic mechanical properties of epoxy syntactic foams reinforced by short carbon fiber. Polymer Composites, 2016. 37(7): p. 1960-1970.

[41] Hu, G. and D. Yu, Tensile, thermal and dynamic mechanical properties of hollow polymer particle-filled epoxy syntactic foam. Materials Science and Engineering: A, 2011. 528(15): p. 5177-5183. 